\title{
Assessing the impact of VG30 grade bitumen with and without additive (EVA) on short term aging
}

\author{
Kishan K.Vachhani ${ }^{1}$, Prof. C.B. Mishra ${ }^{2}$ \\ ${ }^{I}$ M.Tech Student, Transportation System Engineering, BVM Engineering College, V.V. Nagar, Anand, India \\ ${ }^{2}$ Associate Professor, Civil Engineering Department, BVM Engineering College, V.V. Nagar, Anand, India
}

\begin{abstract}
India is distinctive among developing countries for its fast-growing service sector and road transport is vital to India's economy, social integration and security needs of the country. Hence roads infrastructure from long run point of view with respect to quality in terms of load carrying capacity, performance, durability and economy is needed. But the aging of bituminous binders is one of the key factors determining the lifetime of an asphalt pavement. Aging in bitumen normally resulted from the weathering of the binder due to oxidation. Bitumen hardening occurs progressively during asphalt production, transportation, paving operation and thereafter during its service life. Gradual loss of visco-elastic properties of bitumen is due to hardening of asphalt material, consequently an increasing traffic loading will hasten performance failure of the pavement, frequency of traffic and changing environment.

In the present study Ethylene Vinyl Acetate (EVA), a plastomer were used in various percentages (2 to 4\%) as modifiers in VG30 grade bitumen for determine short term aging. The changing effects on physical properties in terms of the bituminous binders with and without EVA were measured before aging and after aging were measured. The results show that after ageing softening point increases, penetration decreases and elastic recovery increases with increasing percentage of EVA. The losses of volatile fractions recorded are within permissible limits of codal provision. Utilization of such modifier can be beneficial to road projects.
\end{abstract}

Keywords: Bitumen, aging, oxidation, penetration, softening point, elastic recovery, viscosity.

\section{Introduction}

"The development of any economy anywhere in the world needs sophisticated infrastructure that roads, airport runways and parking lots, so one can see the value of bitumen. India, huge investments are being made to expand the existing road infrastructure and also to develop new highways for better connectivity as well as to serve the economic activity in the country. The demand of bitumen has exceeded the bitumen production and supply. India is having $98 \%$ flexible pavement which is an important asset. They are always prone to various distresses during its service life caused by loading and weather-induced stresses. High temperature rutting and low temperature cracking are instances of these distresses, the formation of which is known to be highly dependent on performance of the bitumen of the asphalt mixtures. The aging of bituminous binders is one of the key factors determining the lifetime of an asphalt pavement. The process of aging involves chemical and/or physical property changes that usually make bituminous materials harder and more brittle, thus increasing risk of pavement failure.

The durability and the satisfactory performance of pavements demand the right type of bitumen with and without the addition of additives to cope up with the special problems of short term aging under extreme climatic conditions and increased traffic density.

In the present study, an attempt is made to focus on evaluating the physical properties in the laboratory of VG 30 grade bitumen with and without additive (ethylene vinyl acetate copolymer). Also the impact of short term aging is carried out using thin film oven test (TFOT) for bitumen with and without additives. The outcomes of results are compared between the un-aged bitumen with and without modifier and aged modified bitumen samples (with and without EVA).

\section{Some Selected Previous Research Work:}

2.1 Airey (2002) reported that the rheological properties of bitumen are improved by means of EVA polymer modification. The semi crystalline EVA copolymer provides the modification of bitumen through the crystallization of rigid three-dimensional networks within the bitumen. Conventional penetration, softening point, frass, ductility and high temperature viscosity tests have demonstrated the increased stiffness (hardness) and improved temperature susceptibility of the EVA PMBs.[1]

2.2 Claudio Brovelli, LoicHilliou, YacineHemar, Jorge Pais, Paulo Pereira, Maurizio Crispino (2013) stated EVA modified bitumen have the ability to provide improved resistance to rutting in hot-mix asphalt compared to conventional bitumen along with improved compatibility, safer handling and better workability 
compared to the SBS and SBR modifiers. Some grades of EVA also increase the resistance to damage caused by fuel spillages and pose no problems with future recycling of the material. However, it should be noted that the properties of EVA vary for different grades depending on the chain length and molecular weight of the polymer, the vinyl acetate (VA) monomer content and the crystallinity. In terms of the EVAs the VA content and melt flow rate (MFR) are as important as the Styrene content and linear or radial structure in SBSs, when determining specific properties. EVA modified bitumen is also more heat stable and does not deteriorate at elevated temperatures during storage as fast as SBR and SBS modified bitumen products. Storage stability will therefore be better than that of SBS and SBR.[2]

2.3 Gonzalez et al. (2004) revealed that the visco-elastic properties of a 60/70 penetration grade bitumen are improved when either a virgin EVA or a recycled EVA copolymer of similar vinyl acetate content are mixed with it. Risk of cracking at low temperatures and rutting at high temperatures, are both reduced. Better viscoelastic features are obtained with the bitumen modified with recycled EVA, probably due to the presence of carbon black, which acts like a filler in this material. Stability tests performed combining oscillatory flow and microscopy results disclose that blends with the higher polymer proportion (3\%) are susceptible of phase separation after $24 \mathrm{~h}$ of storage at $165 \mathrm{C}$, but $1 \%$ blends are stable for at least 4 days. A general evaluation of the results indicates that the performance of this bitumen as a binder for road pavement is particularly improved when $1 \%$ of recycled EVA or virgin EVA is added. [3]

2.4 Morales and Partal (2004) reported that the viscous properties of bitumen, at high temperature, are improved by adding recycled EVA copolymer in amounts that depend on bitumen penetration grade. Moreover, significant micro structural changes, related to the development of a polymer-rich phase, tend to occur in the bitumen as polymer concentration increased. These changes in microstructure have a significant influence on the flow behavior of the binder and on its in-service performance. [4]

2.5 Praveen Kumar, M.R. Maurya, Manoj Gupta \& Maninder Singh (2012) stated that the challenge in physical property characterization is to develop physical tests that can satisfactorily characterize key asphalt binder parameters and how these parameters change throughout the life of an HMA pavement. In India, the methods for rheological characterization of bituminous binders are inadequate to characterize the bitumen. Hence a complete rheological study and characterization of bitumen using dynamic shear rheometer would be helpful. Also there is limited insight about the chemistry of modified bitumen. Ethylene Vinyl Acetate (EVA), a plastomer; Linear Styrene Butadiene Styrene (SBS), an elastomer and Crumb Rubber (CR) were used in the study. The changes in rheological and chemical properties of 60/70 and 80/100 grades bitumen modified with different percentage of CR, EVA and SBS (2 to 8 per cent) were studied. The rheological properties of the bituminous binders in terms of their complex modulus $\left(\mathrm{G}^{*}\right)$, stiffness and overall resistance to deformation, storage modulus $\left(\mathrm{G}^{\prime}\right)$, binder elasticity, loss modulus (G'),viscous behavior and phase angle $(\delta)$, visco-elastic behavior were measured. Testing was performed at temperatures ranging from $46^{\circ} \mathrm{Cto} 82^{\circ} \mathrm{C}$ in increments of $6^{\circ} \mathrm{C}$ at a frequency of $10 \mathrm{rad} / \mathrm{sec}$. The chemistry was studied using infrared spectroscopy. [5]

2.6 Praveen Kumar, Tanveer Khan and Maninder Singh (2013) of Department of Civil Engineering, IIT Roorkee, India, stated that the deterioration of the flexible pavements are also due to extreme climatic conditions prevailing in the country in addition to the heavy traffic. The polymer modification of the bitumen can improve the quality of binders and enhance the properties of binders used for the construction of pavements. Ageing of bitumen is one of the principal factors causing the failure of bituminous pavement components due to the prolonged exposure to air and environmental conditions. Ageing are of two types i.e. short term and long term. Short-term ageing occurs when binder is mixed with aggregates in a mixing plant. Long-term ageing occurs after pavement construction and is generally due to environmental exposure and loading. The properties of bitumen mainly depend on the age of bitumen. Therefore there is a need to study the properties of modified bitumen before and after ageing. In this paper the physical properties of EVA (Ethyl Vinyl Acetate) modified bitumen is discussed, optimum dose is determined and the effect of ageing on the binder prepared using the optimum dose is evaluated. [6]

\subsection{Materials:}

\section{Experimental Programme}

The materials which are used in this work are as follows.

\section{i. Bitumen:}

Viscosity Grade -30 (VG-30) bitumen supplied by the Tiki Tar Industries, Halol Vadodara district is taken for the study. VG-30 grade bitumen is a thermoplastic material primarily used to construct extra heavy duty bitumen pavements to have greater mix of ease design and better road performance that need to endure 
substantial traffic loads. Dynamic viscosity tests are conducted at $60^{\circ} \mathrm{C}$ and $135^{\circ} \mathrm{C}$, which represent the temperature of road surface for warmer climate during summer and mixing temperature respectively.

\section{ii. Modifiers:}

Ethyl Vinyl Acetate (EVA) copolymer, available as pellets 4 to $5 \mathrm{~mm}$ in diameter supplied by Tiki Tar Industries, Halol, Vadodara district was used to modify the conventional VG30 grade bitumen. EVA is a polymeric plastomer which consists of two monomers ethylene and vinyl-acetate (VA). The copolymers are polar and together with the maltenes from the bitumen will dictate the compatibility and adhesive properties of the binder. EVA modified bitumen have the ability to provide improved resistance to rutting in hot-mix asphalt compared to conventional bitumen along with improved compatibility, safer handling and better workability. EVAs have improved clarity, low temperature flexibility, stress-crack resistance, and impact strength. Structure of ethylene vinyl acetate is as shown below.

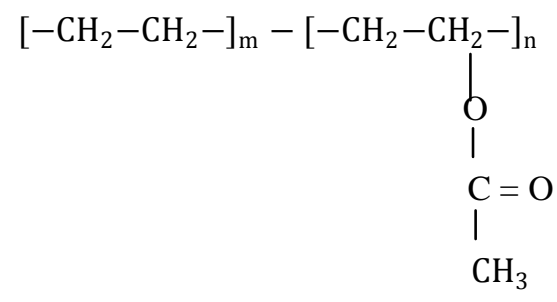

\section{b. Preparation Of Modified Binders:}

In preparing the modified binders, about $500 \mathrm{~g}$ of the bitumen was heated to fluid condition in a 1.5 litre capacity metal container. The mixing was performed in the laboratory using an oven fitted with a mechanical stirrer and rotated at $1550 \mathrm{rpm}$ for mixing the bitumen and modifiers. For preparation of EVA blends, bitumen was heated to a temperature of $180{ }^{\circ} \mathrm{C}$. As the bitumen attained a temperature of $180{ }^{\circ} \mathrm{C}$, the different EVA polymer contents by mass ( 2 to $4 \%$ ) were added to the bitumen and vigorously agitated. The temperature was maintained between $175^{\circ} \mathrm{C}$ to $180^{\circ} \mathrm{C}$ and mixing was then continued for $80-90$ minutes.

\section{c. Testing:}

Rotational Viscometer was used for determining the dynamic viscosities of the samples at $135{ }^{\circ} \mathrm{C}$ for 5 min at $20 \mathrm{rpm}$. Aging of the binders was performed by Thin Film Oven Test TFOT, as specified by IRC: SP 532002.

\subsection{Before ageing:}

\section{Test Results And Discussion:}

Table 1: Physical properties of un-aged bitumen

\begin{tabular}{|c|c|c|c|c|c|}
\hline Binder type & $\begin{array}{l}\text { Penetration at } 25 \\
{ }^{\circ} \mathrm{C} \\
(\mathrm{mm})(\mathrm{IS}: \\
1978)\end{array}$ & $\begin{array}{l}\text { Softening point } \\
\left({ }^{\circ} \mathrm{C}\right) \\
\text { (IS: } 1209-1978)\end{array}$ & $\begin{array}{l}\text { Elastic recovery } \\
\left.\text { at } 15{ }^{\circ} \mathrm{C}, \quad \%\right) \\
\text { (IRC-SP-53- } \\
2010 \text { ) }\end{array}$ & $\begin{array}{l}\text { Dynamic Viscosity in } \\
\text { Poise (ASTM D4402- } \\
\text { 06) conducted at } \\
\text { temperature }\end{array}$ & $\begin{array}{l}\text { Specific gravity } \\
\text { (IS: 1202-1978) }\end{array}$ \\
\hline VG-30 & 52 & 50 & 20 & $@ 60^{\circ} \mathrm{C}=2.6$ & 1.39 \\
\hline $2 \% \mathrm{EVA}$ & 35 & 56 & 44 & $@ 135^{\circ} \mathrm{C}=6.2$ & 1.033 \\
\hline $3 \% \mathrm{EVA}$ & 33 & 59 & 52 & $@ 135^{\circ} \mathrm{C}=6.8$ & 1.032 \\
\hline 4\%EVA & 30 & 64 & 60 & $@ 135^{\circ} \mathrm{C}=7.9$ & 1.030 \\
\hline
\end{tabular}

\subsection{Physical properties of un-aged bitumen:}

\subsubsection{Penetration test:}

The penetration values of bitumen modified with different percentage of Ethylene vinyl acetate (EVA) and are shown in Table 1. The penetration values are decreasing significantly for VG30 bitumen mixed with EVA as the concentration of it increases. This is an indication that the chemistry has changed the property, as stiffness has increased; enhanced condition of temperature susceptible is noted thereby increasing the workability of bituminous mix. [10]

\subsubsection{Softening point test}

Results shows the softening point increases with increase in percentage of modifiers as the bitumen becomes increasingly viscous and increases better rutting resistance. [11] 


\subsubsection{Elastic recovery results}

The elastic recovery test was performed as per IRC: SP: 53-2002 and was found to increase with increase in percentage of modifiers thereby improving binder resistance to rutting. [9]

\subsubsection{Specific gravity test results}

The results show that the specific gravity values decreases significantly by modifying the bitumen. The density of bitumen is greatly influenced by its chemical composition. The reduction signifies the decrease in aromatic type mineral impurities with reduction in density thereby maintains stiffer bitumen in hotter temperatures. It substantially reduces rutting and increases stability. [12]

\subsubsection{Viscosity results}

The viscosity is a fundamental engineering parameter which shows increases on introduction of EVA and this contributes to easily pump the material into the HMA plant for mixing and can be placed to the site for roadwork. [7]

\subsection{After aging}

Table 2: Physical properties after TFOT ageing

\begin{tabular}{|l|l|l|l|l|}
\hline Binder type & $\begin{array}{l}\text { Penetration at } 25^{\circ} \mathrm{C} \\
(\mathrm{mm}) \\
(\text { IS: } 1203-1978)\end{array}$ & $\begin{array}{l}\text { Softening point, } \\
\left({ }^{\circ} \mathrm{C}\right) \\
(\text { IS: 1209-1978) }\end{array}$ & $\begin{array}{l}\text { Elastic } \\
\text { recovery at } \\
\begin{array}{l}5^{\circ} \mathrm{C},(\%) \\
\text { (IRC-SP-53- } \\
2010)\end{array}\end{array}$ & $\begin{array}{l}\text { \%Loss of } \\
\text { weight after } \\
\text { TFOT } \\
\text { (ASTM } \\
\text { D1754) }\end{array}$ \\
\hline VG-30 & 48 & 51 & 16 & 0.05 \\
\hline $2 \%$ EVA & 32 & 57 & 38 & 0.045 \\
\hline $3 \%$ EVA & 30 & 60 & 47 & 0.04 \\
\hline $4 \%$ EVA & 27 & 64.5 & 55 & 0.03 \\
\hline
\end{tabular}

\subsection{Physical properties after aging (table 2):}

\subsubsection{Penetration test}

The material becomes stiffer after evaporation of volatile, material ageing hardens and thus penetration value decreases and the value decreases as the percentage of modifier. [10]

\subsubsection{Softening point test}

There is an increase in softening point noted with increasing modifier content. [11]

\subsubsection{Elastic recovery test}

The result obtained shows an increasing pattern which indicates the material as more flexible to binder. [9]

\subsubsection{Loss in weight}

The loss of volatile fractions contributes to the difference in weights between un-aged and aged sample. The maximum loss in weight is within the permissible limit as laid down in codal provision i.e. less than 1\%. [7]

\section{Conclusions:}

The laboratory investigations indicates that short-term aging of the bitumen shows the physical hardness of the binder properties changing after simulating the base bitumen to aging using TFOT, reducing binder penetration, increasing softening points, increasing elastic recovery and the loss of volatile fractions contributes to the difference in weights between un-aged and aged sample. Aging increases the binder hardness; this could be attributed to the increase stiffness of the binder after the TFOT. The elastic recovery increases with increase in percentage of EVA and is observed at $4 \%$. Higher value of elastic recovery indicates more flexibility to the binder and will increase the life of pavement at low temperature.EVA modified binders can be used in very high temperature and heavy traffic areas and states the climatic conditions in which each one should be used beneficially. It has got opportunities for road sector engineering companies.

\section{References:}

[1]. Airey, G.D. (2002). "Rheological Evaluation of Ethylene Vinyl Acetate Polymer Modified Bitumens", Journal of Construction and Building Materials, Elsevier Science Ltd, 16, 473-487.

[2]. Claudio Brovelli, LoicHilliou, YacineHemar, Jorge Pais, Paulo Pereira, Maurizio Crispino (2013), "Rheological characteristics of EVA modified bitumen and their correlations with bitumen concrete properties" / Construction and Building Materials 48 (2013) 1202-1208, Elsevier Science Direct.

[3]. Gonzalez, O., Muno, M. and Santama, A. (2004). "Rheology and Stability of Bitumen-EVA Blends", European Polymer Journal, Elsevier Science Ltd, 40, 2365-2372.

[4]. Morales, M. and Partal, P. (2004). "Viscous properties and microstructure of recycled EVA modified bitumen", Fuel, Elsevier Science Ltd, 83, 31-38.

[5]. Praveen Kumar, M.R. Maurya, Manoj Gupta \&Maninder Singh(2012) "Lab study on chemical and rheological changes in modified binders" Highway Research Journal, January - June 2012 
[6]. Praveen Kumar, Tanveer, Khan and Maninder Singh (2013), "Study on EVA modified bitumen” Elixir Chem. Engg. 54A (2013) 12616-12618

[7]. ASTM D4402 - 06 "Standard Test Method for Viscosity Determination of Asphalt at Elevated Temperatures Using a Rotational Viscometer".

[8]. ASTM D1754, "Test Method for Effect of Heat and Air on Thin Film of Asphalt (TFOT)".

[9]. IRC-SP-53-2010, "polymer and rubber modified bitumen specification -determination of elastic recovery"

[10]. IS: 1203-1978, "The standard test method for penetration of bituminous materials".

[11]. IS: 1209-1978, "The standard test method for softening point of bitumen (ring and-ball apparatus)".

[12]. IS: 1202-1978, "The standard test method for specific gravity and density of semi-solid bituminous materials (pycnometer method)". 